eCommons@AKU

May 2018

\title{
Environment and Neurological Diseases: Growing Evidence for Direct Relationship
}

Mohammad Wasay

Aga Khan University, mohammad.wasay@aku.edu

Adeel Khoja

Aga Khan University, adeel.khoja@aku.edu

Follow this and additional works at: https://ecommons.aku.edu/pakistan_fhs_mc_med_neurol Part of the Neurology Commons

\section{Recommended Citation}

Wasay, M., Khoja, A. (2018). Environment and Neurological Diseases: Growing Evidence for Direct Relationship. JCPSP:Journal of the College of Physicians and Surgeons--Pakistan., 28(5), 337-338.

Available at: https://ecommons.aku.edu/pakistan_fhs_mc_med_neurol/125 


\section{Environment and Neurological Diseases: Growing Evidence for Direct Relationship}

Mohammad Wasay and Adeel Khoja

Exposure to air pollution has been implicated in a number of adverse health outcomes. There is increasing evidence that point towards association of airborne pollutant exposure with respiratory, cardiovascular, and neurovascular pathology. 1 However, the latter receives the least attention due to paucity on literature examining the impact of polluted environment on cerebrovascular disease. It is important to note that airborne pollutants, such as particulate matter (PM), have the ability to extend beyond the respiratory system and enter the central nervous system (CNS). ${ }^{2}$ The World Health Organization (WHO) has estimated that environmental pollution affects health outcome of every nine out of ten people in the world. ${ }^{3}$

Recent studies have shown air pollution and PM to be associated with neuroinflammation and production of reactive oxygen species (ROS). ${ }^{4}$ Although the mechanisms regarding entry of PM into CNS are not well understood, PM can be trans-located along the pathway of olfactory nerve into the olfactory bulb and can cross permeable brain barriers. ${ }^{5}$ Inhaled pollutant particles are also implicated in neuronal damage through microglial activation and increase in production of cytokines by immune cells of the brain. ${ }^{3} \mathrm{~A}$ study has shown exposure to diesel exhaust particles, a common component of urban air pollution, causing microglial activation, dopaminergic neurotoxicity and increase in ROS production. ${ }^{6}$ These findings suggest strong pro-inflammatory and immune upregulating capacities of air pollution; which may contribute to the pathogenesis of neurodegenerative diseases.

Air pollution is a prevalent proinflammatory stimulus to the CNS and a risk factor for neurodegenerative diseases such as Parkinson's disease (PD) and Alzheimer's disease (AD). ${ }^{5}$ An alarming finding by Braak et al., confirmed the presence of aggregated $\alpha$-synuclein in targeted areas of PD involvement in young cohorts exposed to high air pollution. 7,8 The process of accumulation and fibrillation of soluble $\alpha$-synuclein (pathologic hallmark of PD) and

Department of Medicine, The Aga Khan University Hospital, Karachi.

Correspondence: Prof. Mohammad Wasay, Professor of Neurology, Department of Medicine, The Aga Khan University Hospital, Stadium Road, Karachi.

E-mail: mohammad.wasay@aku.edu

Received: November 27, 2017; Accepted: March 21, 2018.
$A \beta 42$ (pathologic hallmark of $A D$ ) can start in early years despite having no other risk factors for neurodegenerative diseases. ${ }^{7}$ Moreover, carriers of particular alleles have a higher risk of developing $A D$, if they live in a polluted environment. ${ }^{7}$ In a study by Chen et al. carried out on individuals greater than 40 years of age exposed to high concentration of $\mathrm{PM}_{10}$ (above $65 \mu \mathrm{g} / \mathrm{m}^{3}$ ), had 35 times higher chances of developing PD as compared to those exposed to low concentrations of $\mathrm{PM}_{10}$ (below $54 \mu \mathrm{g} / \mathrm{m}^{3}$ ). ${ }^{9}$ Having a residence in an urban area, it can lead to $9 \%$ increase risk of developing PD as compared to those living in rural areas. ${ }^{10}$

The impact of living in a polluted environment on stroke is under-recognised, yet substantial. ${ }^{4}$ According to the Global Burden of Disease Study 2013, 29.2\% of the global stroke burden is attributable to air pollution. ${ }^{11}$ Furthermore, a meta-analysis of 94 studies found stroke hospital admissions to be correlated with high concentrations of carbon monoxide, sulfur dioxide and nitrogen dioxide. ${ }^{12}$ The European Study of Cohorts for Air Pollution Effects reported that even a small increase of about $5 \mu \mathrm{m} / \mathrm{m}^{3}$ in $\mathrm{PM}_{2.5}$ concentration in the air was associated with $19 \%$ increase risk of stroke. ${ }^{4}$

Ground level ozone $\left(\mathrm{O}_{3}\right)$, an urban air pollutant, is also associated with delirious effects on CNS and cognitive impairment. ${ }^{1,5}$ Short- or long-term exposure to $\mathrm{O}_{3}$ may induce an inflammatory response or generate oxidative stress leading to lipid peroxidation in the brain, dopaminergic neurotoxicity and memory deterioration. 2,5 Moreover, high concentration of $\mathrm{O}_{3}$ in the environment was associated with a $211 \%$ increase risk of AD onset. ${ }^{13}$ A recent study showed that people living in a polluted environment having high concentrations of $\mathrm{O}_{3}$ had a $34 \%$ faster rate of cognitive decline annually on the Mini Mental Status Examination (MMSE) as compared to those exposed to lower concentrations of $\mathrm{O}_{3}{ }^{1}$

Increasingly, studies have shown that PM can enter the brain and has been associated with neurovascular pathology. ${ }^{5}$ PM exposure was also reported to cause $138 \%$ increase in risk of $A D$ onset, 13 increase in hospital admissions for migraines by $3.3 \%$, and for headaches by $3.4 \% .14$ Two fractions of PM predominantly affecting CNS are $\mathrm{PM}_{2.5}$ and ultrafine particulate matter (UFPM); both being inhaled on a consistent basis as constituents of air pollution. ${ }^{5}$ Histopathological examinations of postmortem brain tissue from individuals living in highly polluted areas have observed PM to be accumulated in 
neurons in the olfactory bulb and in blood vessels present in the frontal lobe and trigeminal ganglia. ${ }^{7}$ This provides insight into PM being able to pass through the tissue barriers in the lung and brain, subsequently accumulating in the neurons and vessels.

Major roadway proximity was associated with diminished verbal memory, psychomotor speed, language, and executive functioning. ${ }^{4} \mathrm{~A}$ population based cohort study of 2.2 million individuals, demonstrated a significant association between major roadway residence and dementia incidence. ${ }^{15} \mathrm{~A}$ study targeting urban population showed that residents who were exposed to high trafficrelated air pollution had $40 \%$ more chances of developing dementia or AD. 16 The study also reported that increase in incidence was greater than $70 \%$ in a subpopulation excluding younger adults. ${ }^{16}$ These studies highlight the significance of urban air pollution with cognitive decline and neurodegenerative diseases.

These findings may have important implications for Pakistan as according to a recent World Bank report, Pakistan's urban air pollution is among the most severe in the world. ${ }^{17}$ Notable contributors to this pollution are, including but not limited to; burning of biomass solid fuels and untreated wastewater from urban and industrial sources. ${ }^{18}$ The potential role of air pollution in the incidence of neurodegenerative disorders and its adverse impact on health cannot be neglected.

The above discussion highlights the need for additional robust observational and experimental studies highlighting harmful air pollutants and their association with common neurological disorders. Reliable data collections and formidable interventions are key components for reducing air pollution, environmental hazards and neurodegenerative diseases. Safety measures and effective strategies to curb air pollution need to be implemented alongside increase in public awareness.

\section{REFERENCES}

1. Cleary EG, Cifuentes M, Grinstein G, Brugge D, Shea TB. Association of low-level ozone with cognitive decline in older adults. J Alzheimers Dis 2018; 61:67-78.

2. Loane C, Pilinis C, Lekkas TD, Politis M. Ambient particulate matter and its potential neurological consequences. Rev Neurosci 2013; 24:323-35.

3. Jayaraj RL, Rodriguez EA, Wang Y, Block ML. Outdoor ambient air pollution and neurodegenerative diseases: the neuroinflammation hypothesis. Curr Environ Health Rep 2017; 4: 166-79.

4. Babadjouni RM, Hodis DM, Radwanski R, Durazo R, Patel A,
Liu Q, et al. Clinical effects of air pollution on the central nervous system; a review. J ClinNeurosci 2017; 43:16-24.

5. Block ML, Calderón-Garcidueñas L. Air pollution: mechanisms of neuroinflammation and CNS disease. Trends Neurosci 2009; 32:506-16.

6. Block ML. Nanometer size diesel exhaust particles are selectively toxic to dopaminergic neurons: the role of microglia, phagocytosis, and NADPH oxidase. Faseb J 2004; 18:1618-20.

7. Calderón-Garcidueñas $L$, Solt $A C$, Henríquez-Roldán $C$, Torres-Jardón R, Nuse B, Herritt L, et al. Long-term air pollution exposure is associated with neuroinflammation, an altered innate immune response, disruption of the blood-brain barrier, ultrafine particulate deposition, and accumulation of amyloid $\beta$ 42 and $\alpha$-synuclein in children and young adults. Toxicol Pathol 2008; 36:289-310.

8. Braak H, de Vos RA, Bohl J, Del Tredici K. Gastric $\alpha$-synuclein immunoreactive inclusions in Meissner's and Auerbach's plexuses in cases staged for Parkinson's disease-related brain pathology. Neuroscience letters. 2006; 396:67-72.

9. Chen $\mathrm{CY}$, Hung $\mathrm{HJ}$, Chang $\mathrm{KH}$, Hsu $\mathrm{CY}$, Muo $\mathrm{CH}$, Tsai $\mathrm{CH}$, et al. Long-term exposure to air pollution and the incidence of Parkinson's disease: A nested case-control study. PLoS One 2017; $12: 8$.

10. Ritz B, Lee PC, Hansen J. Traffic-related air pollution and Parkinson's disease in Denmark: a case-control study. Environ Health Perspect 2016; 124:351-6.

11. Feigin VL, Roth GA, Naghavi M. Global burden of stroke and risk factors in 188 countries, during 1990-2013: a systematic analysis for the global burden of disease study 2013. Lancet Neurol 2016; 15:913-24.

12. Shah AS, Lee KK, McAllister DA. Short term exposure to air pollution and stroke: systematic review and meta-analysis. BMJ (Clin Res Ed) 2015; 350:1295.

13. Jung CR, Lin YT, Hwang BF. Ozone, particulate matter, and newly diagnosed Alzheimer's disease: a population-based cohort study in Taiwan. J Alzheimers Dis 2015; 44:573-84.

14. Szyszkowicz M, Stieb DM, Rowe BH. Air pollution and daily ED visits for migraine and headache in Edmonton, Canada. Am J Emerg Med 2009; 27:391-6.

15. Chen H, Kwong JC, Copes R, Tu K, Villeneuve PJ, van Donkelaar $\mathrm{A}$, et al. Living near major roads and the incidence of dementia, Parkinson's disease, and multiple sclerosis: a population-based cohort study. Lancet 2017; 389:10070.

16. Oudin A, Forsberg B, Adolfsson AN, Lind N, Modig L, Nordin M, et al. Traffic-related air pollution and dementia incidence in northern Sweden: a longitudinal study. Environ Health Persp 2016; 124:306-12.

17. https://www.dawn.com/news/1119031 (cited on 26/12/17).

18. Ilyas SZ, Khattak AI, Nasir SM, Qurashi T, Durrani R. Air pollution assessment in urban areas and its impact on human health in the city of Quetta, Pakistan. Clean Technol Environ Policy 2010; 12:291-9. 